\title{
Design, development and characterization of serratiopeptidase loaded albumin nanoparticles
}

\author{
Harpreet Kaur, Amit Singh* \\ Department of Pharmaceutics, Lovely Faculty of Applied Medical Sciences, Lovely Professional University, Jalandhar-Delhi G.T. Road (NH-1), \\ Phagwara-144402, Punjab, India.
}

\section{ARTICLE INFO}

Article history:

Received on: 18/11/2014

Revised on: 09/12/2014

Accepted on: 11/01/2015

Available online: 27/02/2015

\section{Key words:}

Albumin nanoparticles, Serratiopeptidase, Solvent desolvation, enzyme activity.

\begin{abstract}
In recent years, albumin nanoparticles have been widely studied for delivery of various active pharmaceuticals with enhanced accumulation at the site of inflammation. Albumin is a versatile carrier to prepare nanoparticles and nanospheres due to its easy availability in pure form, biodegradability non-toxic and non-immunogenic nature. The mechanism of action of Serratiopeptidase appears to be hydrolysis of histamine, bradykinin and serotonin. Serratiopeptidase also has a proteolytic and fibrinolytic effect. Protein i.e. bovine serum albumin was used to entrap serratiopeptidase enzyme. Protease activity of the enzyme was checked and method was validated to access the active enzyme concentration during formulation. Solvent desolvation method was used for the preparation of BSA nanoparticles. Effect of buffer $\mathrm{pH}$ was checked on the enzyme activity. Chloroform was selected and used as solvent for nanoparticle preparation. Effect of various variables such as concentration of BSA, agitation rate, glutarldehyde concentration, time of crosslinking etc. on the formulation was studied. Formed nanoparticles were characterized for drug content, in-vitro release, entrapment efficiency, particle size and size distribution. The formed serratiopeptidase loaded albumin nanoparticles may be used for the treatment of arthritis.
\end{abstract}

\section{INTRODUCTION}

There are many problems associated with drugs such as poor solubility, toxicity, instability, incompatibility and poor penetration (Patel and Agarwal, 2011). These problems give emphasis on the need of development of delivery system to deliver the drug efficiently. Various delivery systems such as nanoparticles, nanospheres have emerged as promising approaches for hydrophilic as well as hydrophobic drugs. Nanoparticles for drug delivery can be formulated using synthetic or semisynthetic polymers (Mohanraj and Chen, 2006), containing drug adsorbed onto the surface or embedded within the matrix (Jahanshahi et al., 2008). These systems offers better site specific targeting, protection from degradation of drug, controlled drug release along with excellence in many other

\section{* Corresponding Author}

Amit Singh, Department of Pharmaceutics, Lovely Faculty of Applied

Medical Sciences, Lovely Professional University, Jalandhar-Delhi G.T.

Road (NH-1), Phagwara-144402, Punjab, India.

Email:amit.16784@lpu.co.in aspects (Biju et al., 2006., Gangwar et al., 2012). Albumin is protein carrier, used for nanoparticle preparation due to its easy availability in pure form, biodegradability, non-toxicity and nonimmunogenicity (Kratz et al., 1997). Albumin nanoparticles are easy to prepare in different sizes. Various reactive groups (thiol, amino, and carboxylic groups) present on albumin can be used for attachment of drug molecules and targeting moieties (Jahanshahi et al., 2008). Required amount of drug can be incorporated into the particle matrix because of the presence of different binding sites (Vyas and Khar, 2002). Serratiopeptidase is bacterial enzyme which has been reported for various pharmacological activities, more importantly, reduction of inflammation and improvement of microcirculation. Hence, it is used for the treatment of pain and inflammation associated conditions such as arthritis. Serratiopeptidase is mainly formulated as enteric coated tablet to protect gastric degradation of drug and thus, provides improved bioavailability. The enzyme delivery has been targeted by entrapping in various polymers such as Eudragit, phospholipids, alginate, chitosan etc. for various sites. BSA had been reported to 
be accumulated at the inflammatory sites in the arthritis (Wunder et al., 2003). This generated idea to entrap the drug, serratiopeptidase in the BSA nanoparticles in order to enhance the bioavailability and more importantly, target the enzyme at arthritic joints.Albumin Nanoparticles can be prepared by various techniques such as desolvation (Sailaja et al., 2012), emulsification (Eslamian and Shekarriz, 2009), Nano spray drying (Lee et al., 2011), Nab-technology (Cortes and Saura., 2010) etc. In the present study, desolvation technique was used.

\section{MATERIALS AND METHODS}

\section{Material}

The various chemicals used in the present study such as BSA, acetone, casein, calcium acetate, Calcium Citrate Tetrahydrate, Disodium Hydrogen Phosphate, Potassium Dihydrogen Phosphate, Ethanol, FolinandCiocalteu's Phenol Reagent, Glutaraldehyde, Glacial Acetic Acid, L-Tyrosine, Trichloroacetic Acid etc. were purchased from LOBA Chemicals Mumbai, INDIA.

Methods

Physiochemical characterization and identification of Serratiopeptidase

Physical Appearance Test

The procured sample of Serratiopeptidase was observed for organoleptic properties such as colour, odour and appearance.

\section{Fourier Transform Infrared Spectroscopy of drug}

The FTIR spectrum of Serratiopeptidase was obtained using Shimadzu model FTIR 8400S spectrophotometer. Finely grounded drug sample was mixed with potassium bromide $(\mathrm{KBr})$ and mixture was pressed under high pressure to form pellet.

\section{Estimation of protein content}

Lowry Method was used for estimation of total protein content of supplied serratiopeptidase. Various concentrations (5-45 $\mu \mathrm{g} / \mathrm{ml}$ ) of enzyme were taken and reacted with Folin-ciocalteau solution. After incubation, absorbance was recorded at $600 \mathrm{~nm}$ using UV Spectrophotometer (Shimadzu Ltd, USA).

\section{Enzyme Activity Assay}

To estimate the enzyme activity of serratiopeptidase, standard assay method was used in which the casein hydrolysing activity of serratiopeptidase is determined by measuring amount of tyrosine liberated in the reaction. The liberated L-tyrosine was reacted with Folin-Ciolcaltea's Phenol Reagent and intensity of colour produced was measured by UV spectrophotometer at 660 $\mathrm{nm}$. A standard curve of L-tyrosine was prepared to estimate the amount of L-tyrosine liberated in the reaction. To estimate the enzyme activity, $5 \mathrm{ml}$ of $0.65 \%$ casein solution was equilibrated in a water bath at $37^{\circ} \mathrm{C}$ for 5 minutes and then the enzyme solution was added. The reaction was quenched by adding $5 \mathrm{ml}$ of the TCA reagent, the reaction content was filtered using $0.45 \mu \mathrm{m}$ polyethersulfone syringe filters to remove any particulate matter in the mixture. To the filtrates, $5 \mathrm{ml}$ of sodium carbonate solution was added and then $1 \mathrm{ml}$ of Folin's reagent was added immediately afterwards. The intensity of colour produced was measured using spectrophotometer and amount of tyrosine liberated was determined by standard curve.

\section{Effect of pH on enzyme activity}

The buffer $\mathrm{pH}$ has pronounced effect on the preparation of albumin nanoparticles. A suitable buffer for the preparation of albumin nanoparticles containing serratiopeptidase, was selected by testing effect of buffer $\mathrm{pH}$ on serratiopeptidase activity. Different buffers ( $5 \mathrm{ml}$ each) were prepared with different $\mathrm{pH}$ i.e. 4, 5, 6, 7, 8, 9, 10, 11 and serratiopeptidase (10 mg) was dissolved in each buffer. After incubation for 1h, enzyme activity assay was performed and activity was calculated as described above.

\section{Selection of solvent for preparation of albumin nanoparticles}

For the selection of a suitable solvent for preparation of albumin nanoparticles, different organic solvents such as acetone, chloroform and ethanol etc. were tried for the precipitation of albumin from aqueous solution. The solvents were separately added drop wise in the albumin solutions, till the slight turbidity developed. The solvent which produced slight turbidity without settling on storage for overnight was selected for further studies.

\section{Preparation of Albumin Nanoparticles}

Desolvation method was used for the preparation of Albumin nanoparticles (Jahanshahi et al., 2008). Bovine serum albumin $(15 \mathrm{mg})$ and serratiopeptidase $(10 \mathrm{mg})$ were accurately weighed and dissolved in selected buffer and kept on magnetic stirrer at $400 \mathrm{rpm}$. Then acetone was added at different time intervals until solution became turbid. $8 \%$ glutaraldehyde $(50 \mu \mathrm{l})$ was added for cross-linking.

\section{Effect of BSA concentration on particle size}

15,20 and $30 \mathrm{mg} / \mathrm{ml}$ solutions of BSA were prepared and serratiopeptidase $(10 \mathrm{mg})$ was incorporated into it. Nanoparticles were prepared as described above using acetone as antisolvent and glutardehyde as cross linking agent. Particle size was determined using Zetasizer (Malvern ${ }^{\mathrm{TM}}$ ).

\section{Effect of glutaraldehyde concentration on entrapment}

Different concentrations of glutaraldehyde i.e. 50, 100, $150,200 \mu \mathrm{l}$ of $8 \%$ solution were tried for the cross linking of albumin nanoparticles, prepared by desolvation method. Entrapment efficiency of the particles was analysed.

\section{Design of Experiment}

Formulation optimization was carried out by using response surface methodology central composite, quadratic design. Twenty formulations were prepared according to the design (Table 1). Entrapment efficiency and particle size were the parameters used for formulation optimization. 
Table 1: Composition of albumin nanoparticles according to the central composite design.

\begin{tabular}{ccccc}
\hline S. No. & $\begin{array}{c}\text { Formulation } \\
\text { code }\end{array}$ & BSA $(\mathbf{m g})$ & $\begin{array}{c}\text { Acetone } \\
(\mathbf{m l})\end{array}$ & $\begin{array}{c}\text { Glutaraldehyde } \\
(\boldsymbol{\mu l})\end{array}$ \\
\hline 1 & F1 & 20 & 7 & 40 \\
2 & F2 & 6.59104 & 5 & 50 \\
3 & F3 & 10 & 3 & 40 \\
4 & F4 & 15 & 5 & 50 \\
5 & F5 & 15 & 5 & 50 \\
6 & F6 & 15 & 5 & 33.1821 \\
7 & F7 & 15 & 5 & 66.8179 \\
8 & F8 & 10 & 3 & 60 \\
9 & F9 & 10 & 7 & 40 \\
10 & F10 & 20 & 3 & 40 \\
11 & F11 & 15 & 5 & 50 \\
12 & F12 & 15 & 5 & 50 \\
13 & F13 & 15 & 5 & 50 \\
14 & F14 & 15 & 8.36359 & 50 \\
15 & F15 & 20 & 7 & 60 \\
16 & F16 & 23.409 & 5 & 50 \\
17 & F17 & 10 & 7 & 60 \\
18 & F18 & 20 & 3 & 60 \\
19 & F19 & 15 & 1.63641 & 50 \\
20 & F20 & 15 & 5 & 50 \\
\hline
\end{tabular}

\section{Characterization of the prepared Albumin nanoparticles}

Particle size and size distribution

Particle size and size distribution was determined by using a zetasizer (Malvern Zetasizer ${ }^{\mathrm{TM}}$ ). The PDI was observed to determine width of particle size distribution. Zeta potential of the formulation was also determined which indicates the stability of formed nanoparticles.

\section{Entrapment efficiency}

For determination of entrapment efficiency, prepared albumin nanoparticles were centrifuged at $15000 \mathrm{rpm}$. To the supernatant casein and TCA was added and absorbance was taken at $660 \mathrm{~nm}$

Percentage drug entrapment

$$
=\frac{\text { Amount of entrapped drug }}{\text { Total amount of drug }} \times 100
$$

Amount of entrapped drug= Amount of total drug- Amount of unentrapped drug

\section{Transmission Electron Microscopy (TEM)}

The morphology of the albumin nanoparticles was examined by transmission electron microscopy (TEM). A drop of nanoparticle solution was placed onto a carbon-coated copper grid for few minutes and excess solution was removed by filter paper. A drop of $1 \%$ phosphotungstic acid solution was stratified for staining; excess was removed by a tip of filter paper and kept for air dry. The grid was observed by transmission electron microscopy and by using imaging viewer software. The images were analyzed and captured.

\section{In-vitro release study}

Pellet formed after centrifugation at $15000 \mathrm{rpm}$, was suspended in $900 \mathrm{ml}$ of $\mathrm{pH} 6.8$ phosphate buffer at $37^{\circ} \mathrm{C}$ and 90 rpm. After 0, 15, 30, 45, 60, 75, 90, 105, 120, 135, 150, 165, 180, $210,240,270,300,330,360$ minutes, $5 \mathrm{ml}$ of sample was collected and replaced with fresh media. To this sample, $4.5 \mathrm{ml}$ casein solution was added and allowed to stand for 20 minutes at room temperature. Then trichloroacetic acid was added to break the reaction. Absorbance was measured at $280 \mathrm{~nm}$ and $\%$ drug release was calculated.

\section{RESULTS AND DISCUSSION}

\section{Identification and characterization of Serratiopeptidase}

The Serratiopeptidase was identified and characterized by physical appearance and FTIR spectroscopy. The organoleptic properties matched with other reported literature. The recorded FTIR spectrum of procured enzyme has been shown as Fig. 1a. The obtained spectrum was matched with the reported FTIR spectra of serratiopeptidase, which confirmed that the procured enzyme was pure as similar peaks had been reported in publications. Also, spectra were recorded for BSA and prepared formulation (Fig. $1 \mathrm{~b}$ and 1c). There was no significant change in the peaks were observed after entrapping the serratiopeptidase in BSA, which indicated no physical and chemical incompatibility between Serratiopeptidase and BSA.
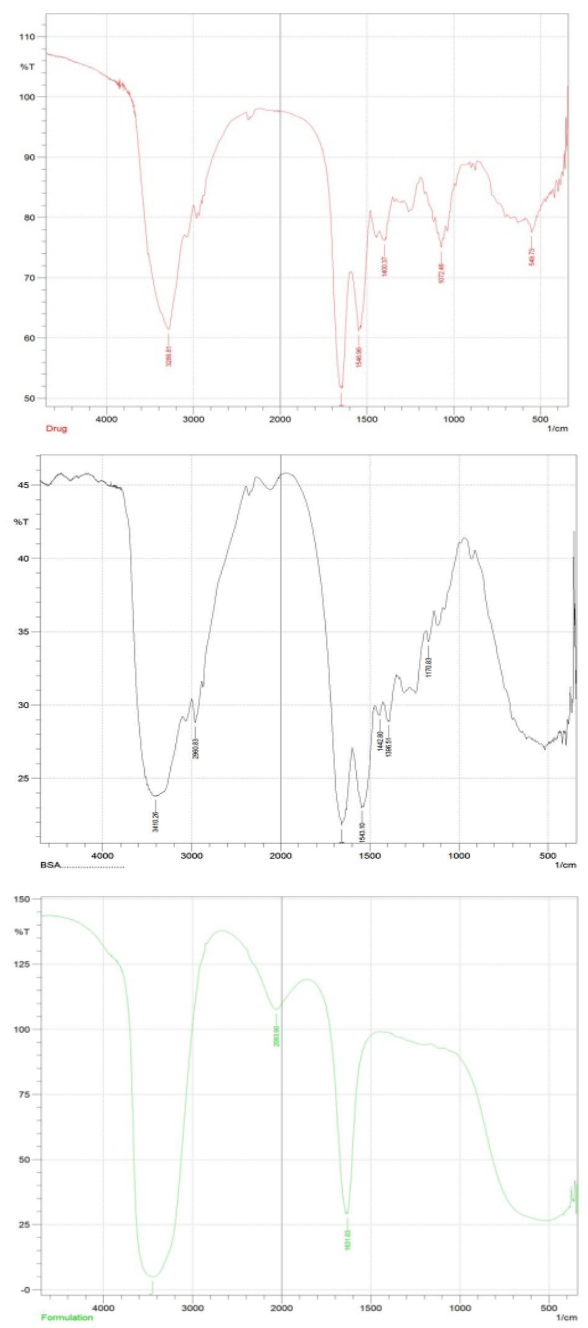

Fig. 1: FTIR spectra of (a) procured serratiopeptidase (b)BSA used in formulation and (c) prepared formulation 


\section{Enzyme Activity Assay}

Assay was performed by protease activity as described in methodology section and amount of tyrosine liberated was calculated using a standard plot of tyrosine (Fig 2). Enzyme activity of various enzyme concentrations was determined as described in methodology and presented in Table 2. A linear relationship was observed between concentration of enzyme and enzyme activity. This proved the reliability and accuracy of the enzyme activity assay method for determination of enzyme concentrations during formulation development.

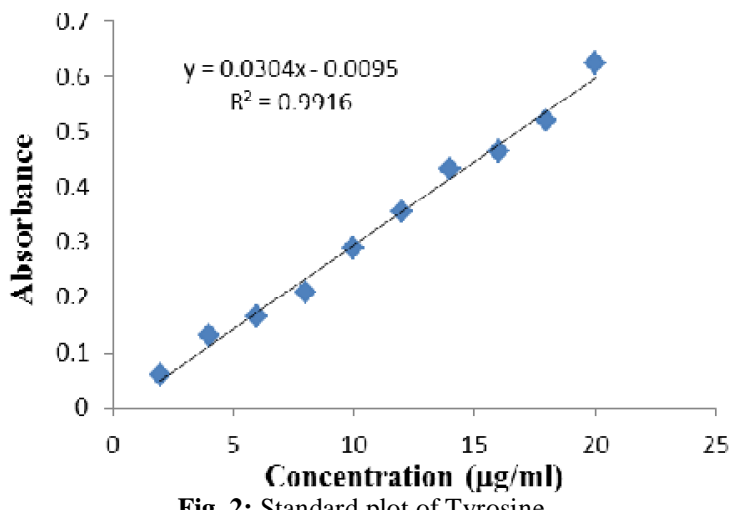

Fig. 2: Standard plot of Tyrosine.

Table 2: Enzymeactivity of various enzyme concentrations.

\begin{tabular}{cc}
\hline Concentration $(\boldsymbol{\mu g} / \mathbf{m l})$ & Enzyme Activity $(\mathbf{U})$ \\
\hline 2 & 0.0021 \\
4 & 0.0042 \\
6 & 0.0053 \\
8 & 0.0066 \\
10 & 0.0091 \\
12 & 0.0111 \\
14 & 0.0135 \\
16 & 0.0145 \\
18 & 0.0162 \\
20 & 0.0194 \\
\hline
\end{tabular}

\section{Effect of pH on enzyme activity}

The effect of $\mathrm{pH}$ was checked on serratiopeptidaseenzyme activity, as described in methodology section. The activity increased with increase of $\mathrm{pH}$ and reached to maximum in the range of 8-9 and decreased thereafter (fig. 3). Hence, buffer of $\mathrm{pH} 8$ was selected for further studies.

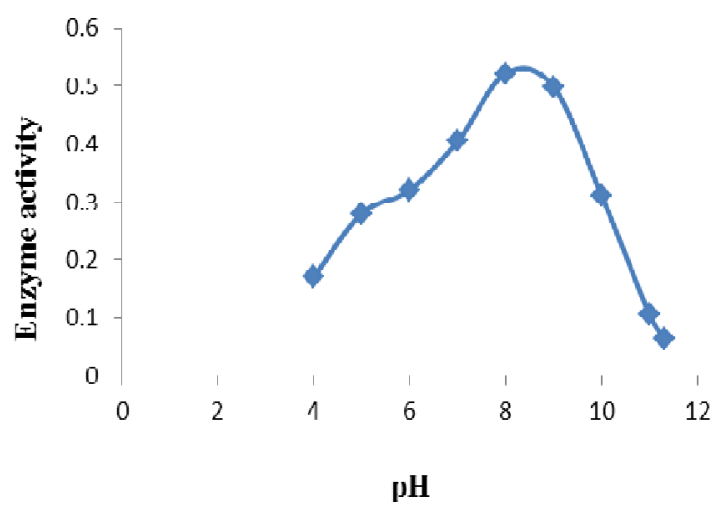

Fig. 3: Effect of bufferpH on activity of serratiopeptidase.

\section{Selection of solvent for preparation of albumin nanoparticles}

Albumin nanoparticles were prepared by desolvation method using different solvents like acetone, chloroform and ethanol. With alcohol very less particle formation was observed whereas chloroform caused aggregation of BSA and hence, macro size particles formed. Nanoparticles prepared with acetone were of nano size and stable, hence, selected for further studies.

\section{Effect of BSA concentration}

Albumin nanoparticles were prepared using different concentrations $(15,20$ and $30 \mathrm{mg} / \mathrm{ml})$ of BSA and the particle size was checked using a zetasizer. It was observed that with increase in BSA concentration particle size also increases. The size distribution curves are shown in fig. $4 \mathrm{a}, 4 \mathrm{~b}$ and $4 \mathrm{c}$.
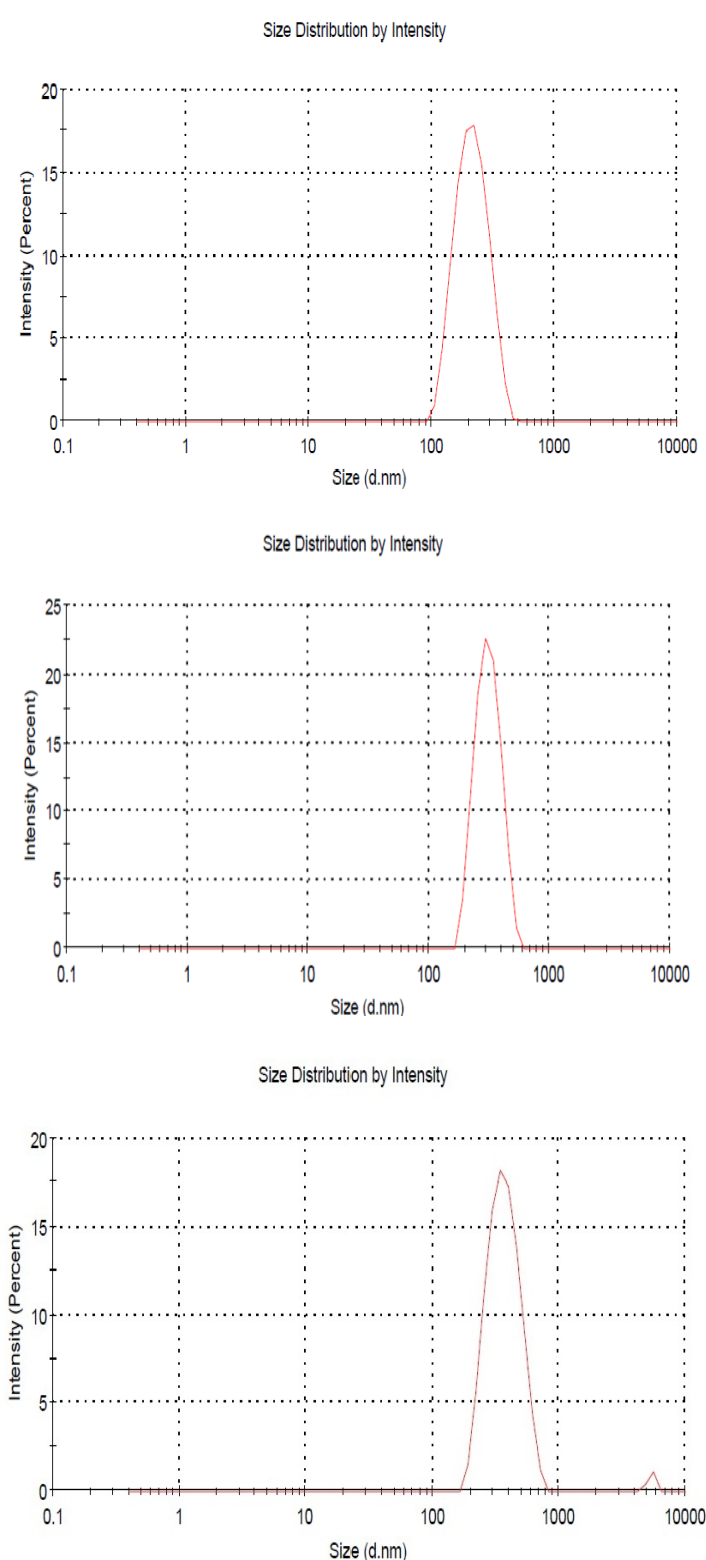

Fig. 4: Zetasizer analysis of the prepared serratiopeptidase loaded albumin nanoparticles at various concentrations of BSA (a) $15 \mathrm{mg} / \mathrm{ml}$, (b) $20 \mathrm{mg} / \mathrm{ml}$, and (c) $30 \mathrm{mg} / \mathrm{ml}$. 
Results had revealed that all formulations were in nano size range. Particle size was found to be minimum in formulation having BSA $15 \mathrm{mg} / \mathrm{ml}$.

BSA concentration less than $15 \mathrm{mg} / \mathrm{ml}$ resulted in less entrapment efficiency, hence $15 \mathrm{mg} / \mathrm{ml}$ concentration was selected. Low value of PDI (0.3-0.4)observed in zetasizer spectra revealed that narrow variation is present between size ranges of prepared nanoparticles.

\section{Optimization of albumin nanoparticles by central composite design}

The design of optimization contained three independent variables $(\mathrm{X} 1, \mathrm{X} 2$, and $\mathrm{X} 3)$ and two dependent variables (Y1 and $\mathrm{Y} 2)$. The $\mathrm{X}$ variables were BSA $(\mathrm{mg})$, Acetone $(\mathrm{ml})$, Glutaraldehyde $(\mu \mathrm{l})$, whereas, the $\mathrm{Y}$ variables were percentage entrapment efficiency and particle size. According to the design, 15 formulations were suggested (Table 3). Each of them were formulated and analyzed for two different responses. The results were analyzed by using polynomial modelling approach using design expert software. Various statistical parameters, ANOVA were applied.

Table 3: Factor combination and responses as per central composite design.

\begin{tabular}{cccccc}
\hline Run & $\begin{array}{c}\text { Amount } \\
\text { of BSA } \\
(\mathbf{m g})\end{array}$ & $\begin{array}{c}\text { Amount of } \\
\text { Acetone } \\
(\mathbf{m l})\end{array}$ & $\begin{array}{c}\text { Amount of } \\
\text { Glutaraldehyde } \\
(\mathbf{\mu l})\end{array}$ & $\mathbf{\%} \mathbf{E E}$ & $\begin{array}{c}\text { Particle } \\
\text { size } \\
(\mathbf{n m})\end{array}$ \\
\hline 1 & 20 & 7 & 40 & 68.66 & 299.2 \\
2 & 6.59 & 5 & 50 & 62 & 360.1 \\
3 & 10 & 3 & 40 & 65 & 200.4 \\
4 & 15 & 5 & 50 & 85 & 194.4 \\
5 & 15 & 5 & 33.18 & 59.23 & 210.7 \\
6 & 15 & 5 & 66.81 & 82.64 & 189.9 \\
7 & 10 & 3 & 60 & 67.1 & 201.6 \\
8 & 10 & 7 & 40 & 69.8 & 205.1 \\
9 & 20 & 3 & 40 & 72.57 & 301.5 \\
10 & 15 & 8.36 & 50 & 79.24 & 215.3 \\
11 & 20 & 7 & 60 & 76.55 & 305.5 \\
12 & 23.40 & 5 & 50 & 87.2 & 353.7 \\
13 & 10 & 7 & 60 & 67.4 & 211.5 \\
14 & 20 & 3 & 60 & 78.6 & 308.8 \\
15 & 15 & 1.63 & 50 & 50 & 334.7 \\
\hline
\end{tabular}

Particle size distribution and PDI was determined using Malvern Zetasizer ${ }^{\mathrm{TM}}$. Results had revealed that all formulations were in nano size range. The formulation 4 and 6 showed good entrapment efficiency along with minimum particle size. Due to lower particle size, formulation 6 was selected as optimum for preparation of serratiopeptidase loaded albumin nanoparticles.Zeta potential of optimized formulation was found to be -27.1 $\mathrm{mV}$, signifying stability of nanoparticles with respect to surface charge.

\section{Transmission Electron Microscopy (TEM)}

The prepared serratiopeptidase loaded albumin nanoparticles were also observed by TEM. At low magnification the particles were viewed as partially aggregated (Fig. 5a), but pictures at higher magnification showed no aggregation (5b). The particles were of nano size having diameter less than $200 \mathrm{~nm}$.
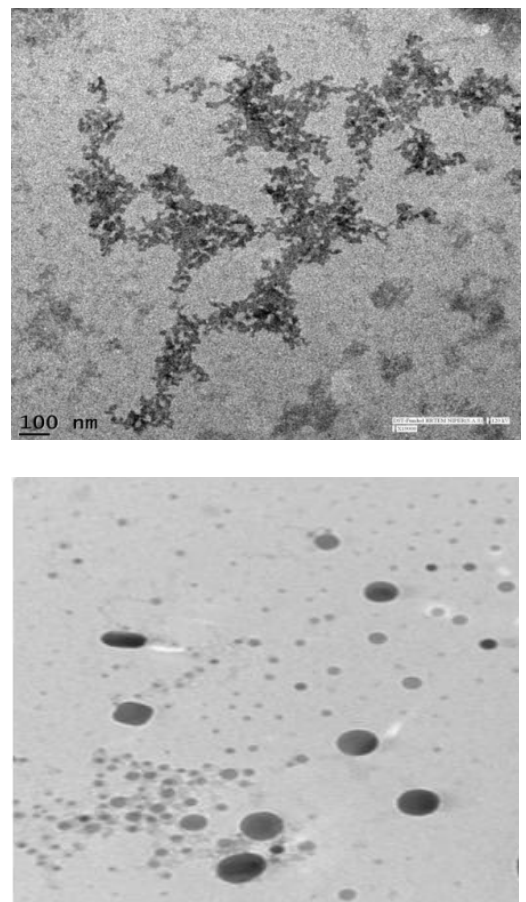

Fig. 5: TEM images of serratiopeptidaes loaded albumin nano particles at different magnifications.

\section{Selection of optimized formulation}

Based on the results of studies carried out to select suitable polymer, solvents and preparation method, different formulations were prepared. The formulations varied in terms of amount of BSA, acetone and glutaraldehyde. A central composite design was employed to obtain 20 different factor combinations and replicates where two independent variables were studied at three levels.

\section{Statistical analysis}

The formulations prepared according to the design were analyzed by using Design Expert ${ }^{\circledR}$ ver. 9.0.2 software package. The effect of formulation variables on the response variables were statistically evaluated by one way ANOVA at 0.05 levels.

The fitting of terms in the polynomial equation indicated that the model was significant and would navigate effectively through the design space. Final polynomial equations for each response variable in terms of actual factors are given below:

$\mathrm{EE}=-135.53682+3.94700 * \mathrm{BSA}+21.85552 *$ Acetone + $4.57972 *$ Glut $-0.13825 * \mathrm{BSA} *$ Acetone $+0.035550 * \mathrm{BSA} *$ Glut $-0.016500 *$ Acetone * Glut $-0.13387 * \mathrm{BSA}^{2}-1.71879$

*Acetone ${ }^{2}-0.046425 *$ Glut $^{2}$

Particle size $=657.13625-55.63303 * \mathrm{BSA}-60.89279 *$ Acetone

$+3.41509 *$ Glut $-0.25250 * \mathrm{BSA} *$ Acetone $+0.015000 * \mathrm{BSA}$

$*$ Glut $+0.026250 *$ Acetone * Glut $+2.05977 * \mathrm{BSA}^{2}+5.63455$

*Acetone ${ }^{2}-0.038723 *$ Glut $^{2}$

Response surface graphs, interaction plots and perturbation plots for entrapment efficiency and particle size as per CCD were obtained from Design Expert ${ }^{\circledast}$ software. Analysis of 
variance for entrapment efficiency and particle size has been given in Table 4 and 5, respectively. These table show that model is significant.The counter plots for the entrapment efficiency and particle size have been shown in Figure 6 and 7, respectively.

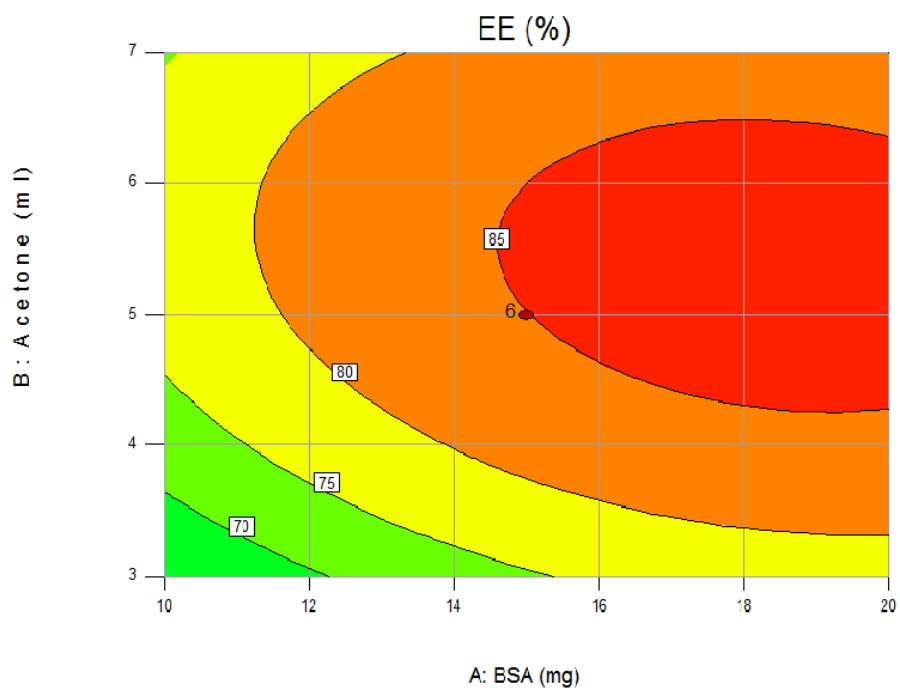

Fig. 6: Contour plot of Entrapment efficiency as per CCD.

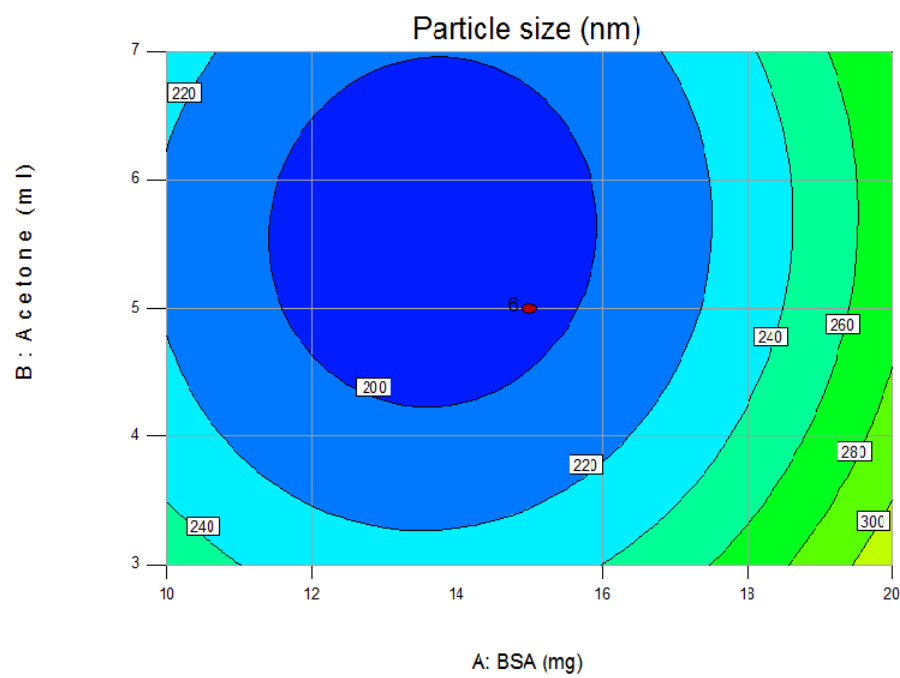

Fig. 7: Representative contour plot of particle size as per central composite design.

Table 4: Analysis of variance table for Entrapment efficiency.

\begin{tabular}{|c|c|c|c|c|c|c|}
\hline \multicolumn{7}{|c|}{ ANOVA for Response Surface Quadratic model } \\
\hline & Sum o & & Mean & $\mathbf{F}$ & p-value & \\
\hline Source & Squares & df & Square & Value & $\begin{array}{l}\text { Prob> } \\
\text { F }\end{array}$ & \\
\hline Model & 1758.74 & 9 & 195.42 & 4.69 & 0.0121 & Significant \\
\hline A-BSA & 353.29 & 1 & 353.29 & 8.47 & 0.0155 & \\
\hline B-Acetone & 170.93 & 1 & 170.93 & 4.10 & 0.0704 & \\
\hline C-Glut & 205.61 & 1 & 205.61 & 4.93 & 0.0507 & \\
\hline $\mathrm{AB}$ & 15.29 & 1 & 15.29 & 0.37 & 0.5583 & \\
\hline $\mathrm{AC}$ & 25.28 & 1 & 25.28 & 0.61 & 0.4543 & \\
\hline $\mathrm{BC}$ & 0.87 & 1 & 0.87 & 0.021 & 0.8879 & \\
\hline$A^{2}$ & 161.41 & 1 & 161.41 & 3.87 & 0.0775 & \\
\hline $\mathrm{B}^{2}$ & 681.19 & 1 & 681.19 & 16.33 & 0.0024 & \\
\hline $\mathrm{C}^{2}$ & 310.60 & 1 & 310.60 & 7.45 & 0.0212 & \\
\hline Residual & 417.01 & 10 & 41.70 & & & \\
\hline Lack of Fit & 417.01 & 5 & 83.40 & & & \\
\hline Pure Error & 0.000 & 5 & 0.000 & & & \\
\hline Cor Total & 2175.75 & 19 & & & & \\
\hline
\end{tabular}

Table 5: Analysis of variance table for Particle size.

\begin{tabular}{|c|c|c|c|c|c|c|}
\hline \multicolumn{7}{|c|}{ ANOVA for Response Surface Quadratic model } \\
\hline & Sum of & & Mean & $\mathbf{F}$ & p-value & \\
\hline Source & Squares & df & Square & Value & Prob $>\mathbf{F}$ & \\
\hline Model & 57924.17 & 9 & 6436.02 & 4.02 & 0.0205 & Significant \\
\hline A-BSA & 10889.44 & 1 & 10889.44 & 6.79 & 0.0262 & \\
\hline B-Acetone & 2693.85 & 1 & 2693.85 & 1.68 & 0.2239 & \\
\hline C-Glut & 13.91 & 1 & 13.91 & 8.67 & 0.9276 & \\
\hline $\mathrm{AB}$ & 51.00 & 1 & 51.00 & 0.032 & 0.8620 & \\
\hline $\mathrm{AC}$ & 4.50 & 1 & 4.50 & 2.808 & 0.9586 & \\
\hline $\mathrm{BC}$ & 2.20 & 1 & 2.20 & 1.376 & 0.9711 & \\
\hline$A^{2}$ & 38213.74 & 1 & 38213.74 & 23.84 & 0.0006 & \\
\hline $\mathrm{B}^{2}$ & 7320.50 & 1 & 7320.50 & 4.57 & 0.0583 & \\
\hline$C^{2}$ & 216.09 & 1 & 216.09 & 0.13 & 0.7211 & \\
\hline Residual & 16026.56 & 10 & 1602.66 & & & \\
\hline Lack of Fit & 16026.56 & 5 & 3205.31 & & & \\
\hline Pure Error & 0.000 & 5 & 0.000 & & & \\
\hline Cor Total & 73950.73 & 19 & & & & \\
\hline
\end{tabular}

\section{Validation of Optimized results}

3-D plots for entrapment efficiency and particle size as shown in Fig. 8 and 9 respectively, represents the optimized range of the components which can provide the best possible entrapment efficiency and particle size in combination. The plots help to define the relationship between the components by observing the response surface. The optimized formulation offered percentage entrapment efficiency of $85 \%$ and particle size of $194.4 \mathrm{~nm}$.

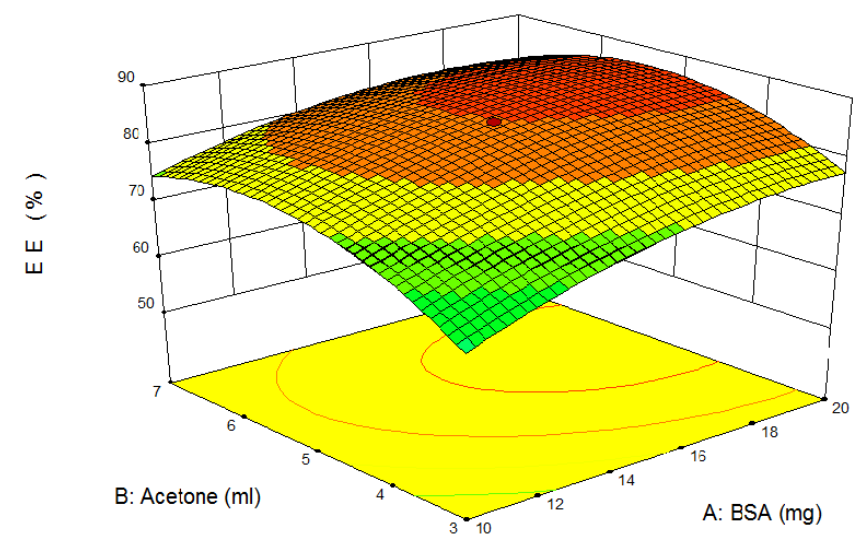

Fig. 8: 3-D plot of optimized formulation for Entrapment efficiency.

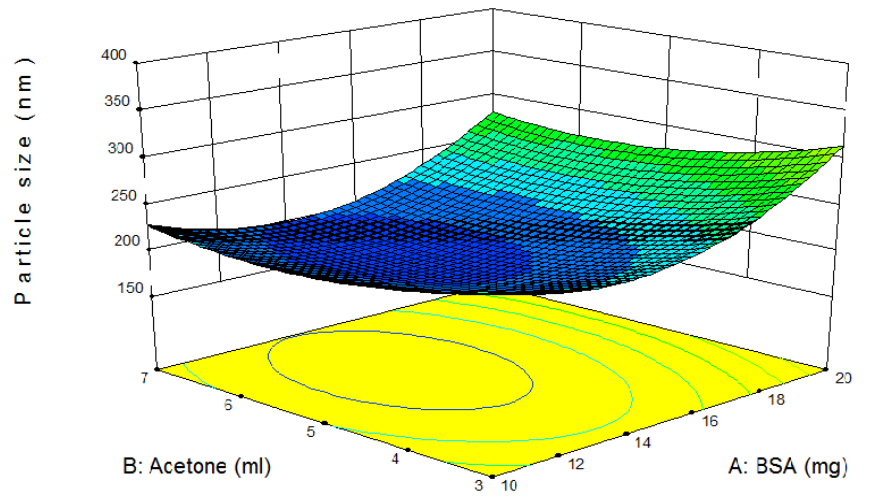

Fig. 9: 3-D plot of optimized formulation.

The 3-D plots along clearly defined the optimal range of the albumin nanoparticles. The repeatability and robustness of the preparation and evaluation of responses were carried out. It was 
ensured that on the basis of Design Expert ${ }^{\circledR}$ software and statistical parameters, the optimized formulation was the best formulation as compared to other formulations which were suggested by the software.

\section{In-vitro release study}

In vitro release profile of optimized formulation and pure drug solution has been summarized in table 5.5. Percentage cumulative amount of albumin nanoparticles was found to be 79.3 and percentage cumulative amount of pure drug was found to be 92.3. Percentage cumulative release plot of pure drug and albumin nanoparticles has been shown in Fig. 10. This indicated that the prepared formulation can be used as sustain release dosage form.

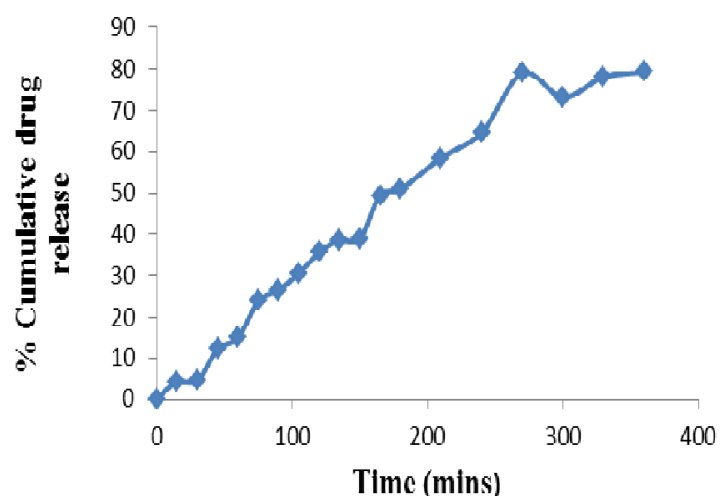

Fig. 10: In vitro release profile of optimized formulation and pure drug.

\section{CONCLUSION}

The serratiopeptidase loaded albumin nanoparticles were prepared and optimized on the basis of entrapment efficiency, particle size and in vitro drug release profile. Optimized albumin nanoparticle formulation was studied for morphology by TEM. The zeta size analysis was carried which presented the vesicle size average range of $194.4 \mathrm{~nm}$. The drug entrapment efficiency of the albumin nanoparticles was analyzed. Entrapment efficiency of optimized formulation was found to be $85 \%$ and percentage drug release was found to be $79.3 \%$. The optimized albumin nanoparticles may be a promising formulation to treat rheumatoid arthritis.

\section{ACKNOWLEDGEMENT}

The authors are grateful toDr. Deepak N. Kapoor (Department of pharmaceutics, Lovely Professional University) for helpful suggestions.

\section{REFERENCES}

Biju SS, Talegaonkar S, Mishra PR, Khar RK. Vesicular system: An overview. Indian J Pharm Sci, 2008; 68: 141-153.

Cortes J, Saura C. Nanoparticle albumin-bound (nab ${ }^{\mathrm{TM}}$ )paclitaxel: improving efficacy and tolerability by targeted drug delivery in metastatic breast cancer. EJC supplements, 2010; 8: 1-10.

Eslamian M, Shekarriz M. Recent advances in nanoparticle preparation by spray and microemulsion methods. Recent Pat Nanotechnol, 2009;3: 99-115.

Gangwar M, Singh R, Goel RK, Nath G. Recent advances in various emerging systems: An overview. Asian Pac J Trop Biomed, 2012; 4: $1176-1188$.

Jahanshahi M, Najafpour G, Rahimnejad M. Applying the Taguchi method for optimized fabrication of bovine serum albumin nanoparticles as drug delivery vehicles. Afr J Biotechnol, 2008; 7: $362-$ 367.

Kratz F, Fichtner I, BeyerU, Schumacher P, Roth T, Fiebig HH, Unger C. Antitumor activity of acid labile transferrin and albumindoxorubicin conjugates in vitroand in vivohuman tumour xenograft models. Eur J Cancer, 1997; 33: 175-179.

Lee SH, Heng D, Ng WK, Chan HK, Tan RBH. Nano spray drying: A novel method for preparing protein nanoparticles for protein therapy. Int JPharm,2011; 403: 192-200.

Mohanraj VJ, Chen Y. Nanoparticles - A Review. Trop J Pharm Res, 2006; 5: 561-573.

Patel VR, Agarwal YK.Nanosuspension: An approach to enhance solubility of drug. J AdvPharm Technol Res, 2011; 2: 81-87.

Sailaja AK, Amareshwar P. Preparation of BSA nanoparticles by desolvation technique using acetone as a desolvating agent.Int J Pharm SciNanotechnol,2012; 5: 1643-1647.

Vyas SP, Khar RK, 2001. Targeted and Controlled Drug Delivery.New Delhi, India:CBS Publishers and Distributor.

Wunder A, Müller-Ladner U, Stelzer EHK, Funk J, Neumann E, Stehle G, Pap T, Sinn H, Gay S, Fiehn C.Albumin-Based Drug Delivery as Novel Therapeutic Approach for Rheumatoid Arthritis. J Immunol, 2003; 170:4793-4801.

\section{How to cite this article:}

Harpreet Kaur, Amit Singh. Design, development and characterization of serratiopeptidase loaded albumin nanoparticles. J App Pharm Sci, 2015; 5 (02): 103-109 